NASA Technical Memorandum 105624

$$
\begin{gathered}
86838 \\
96
\end{gathered}
$$

\title{
Defect Behavior, Carrier Removal and Predicted In-Space Injection Annealing of InP Solar Cells
}

I. Weinberg and C.K. Swartz

Lewis Reseärch Center

Cleveland, Ohio

and

P.J. Drevinsky

Phillips Laborātory

Bedford, Massachusetts

Prepared for the

Fourth International Conference on Indium Phosphide and Related Materials cosponsored by the IEEE and LEOS

Newport, Rhode Island, April 20-24, 1992

\section{N/Sก}




\title{
DEFECT BEHAVIOR, CARRIER REMOVAL AND PREDICTED IN-SPACE INJECTION ANNEALING OF InP SOLAR CELLS
}

I. Weinberg and C.R. Swartz

National Aeronautics and Space Administration

Lewis Regearch Center

Cleveland, Ohio 44135

\author{
P.J. Drevingky \\ Phillipg Laboratory \\ Bedford, MA 01731
}

\section{Abstract}

Defect behavior, observed by DLTS, IB used to predict carrier removal and the effects of simultaneous electron irradiation and injection annealing on the performance. of InP bolar cells. For carrier removal, the number of holes trapped per defect is obtained from measurements of both carrier concentrations and defect concentrations during an isochronal anneal. In addition, from kinetic considerations, the behavior of a dominant defect during injection annealing is used to estimate the degradation expected from exposure to the ambient electron environment in geostationary orbit.

\section{Introduction}

Radiation induced carrier removal is believed to be a significant factor in affecting the performance of InP solar cells (1). In addition, annealing by minority carrier injection (2) should play a Bignificant role in determining the performance of these cello in space. In both cases, the observed effect is believed to be directly related to the behavior of radiation induced defects. However, attempts to relate carrier removal to specific defect behavior have been admittedly speculative (1). With regpect to injection annealing, there have been no published results utilizing defect behavior to predict the effects of injection annealing under the low radiation fluxes typlcal of the space environment. Hence, one objective of the present work lies in using specific defect behavior to predict carrier removal rates. A second objective lies in using defect behavior to predict annealing of InP solar cells by minority carrier injection in the space radiation environment.

\section{Carrier Removal}

Experimental: DITS and carrier concentration measurements were carried out, after $1 \mathrm{MeV}$ electron irradiation, on small mesa diodes which had been processed on the same wafer next to InP solar cells by MOCVD (3). The DLTS and carrier concentration data relevant to the present case are shown in figure 1. The numberg following the hole trap designations $\mathrm{H3}, \mathrm{H4}$ and $\mathrm{H5}$ are the respective defect activation energies as measured in electron volts from the top of the valence band. Carrier removal rates, after $1 \mathrm{MeV}$ electron irradiations were independently determined for similarly processed InP solar cells (4). All celis and diodes were processed by the spire corporation. Additional detaila can be found in the cited refa. $(3,4)$.

Analysis: For a p-type semiconductor, Rc the carrier removal rate is obtiained from the relation

$R c=\Delta p / \phi$

where $\Delta p$ is the reduction in hole concentration due to irradiation at the fluence $\phi$. In general, the measured $\Delta p$ could be attributable to charge compensation and/or the trapping of holes by radiation induced defects. Assuming that the trapping mechanism is predominant, the carrier removal rate 18 expressed by the relation

$R c=\sum_{j} I J T j$

with $I j=N j / \phi$ and $T j=P j / N j$ where Ij $i s$ the introduction rate of the jth defect whose concentration is $\mathrm{Nj}$ at the radiation fluence $\phi$ and $P j$ is the concentration of holes trapped by the jth defect. 
Values for the introduction and trapping rates are obtained from the data of figure 1. From the figure it is seen that variations in carrier concentration correspond to changes in defect concentration during the course of the anneal. For example; at $T>$ $200^{\circ} \mathrm{C}$. an increase in hole concentration coincides with a decrease in the concentration and eventual disappearance of $\mathrm{H} 5$. In this case, the concentration of holes trapped by $\mathrm{H} 5$ is obtained from the jump in hole concentration. In a similar manner, the abrupt jump in hole concentration at $T \sim 100^{\circ} \mathrm{C}$ is correlated with the coincident decrease in the concentration of $\mathrm{H} 3$ and $\mathrm{H} 4$ and the increased concentration of H5. Introduction rates are obtained from the post irradiation defect concentrationg and the fluence $\left(5 \times 10^{45}\right.$ $\mathrm{cm}^{-2}$ ) cited with the figure. In addition, examination of figure 1 at $T$ $>300^{\circ} \mathrm{C}$ indicates the presence of residual trapped holes coincident with the almost complete disappearance of all three defects. This is interpreted as indicating the trapping of the residual holes by unaniealed defects which are not observed by the present DLTS measurements. These latter carriers are included in the carrier removal calculations by adding the term $P$ (res)/ $\phi$ to equation 2 where $P$ (res) is the unannealed carrier concentration at, $\mathrm{T}>300^{\circ} \mathrm{C}$. The results are shown in Table I. In Table II the carrier removal rates, calculated using the data of Table $I$, are compared with independently measured values for InP solar cellg (4). It is seen that there ig reasonable agreement between the calculated and independently measured values. Hence, although additional data would be helpful, the present results tend to confirm the use of simultaneous DLTS and carrier concentration measurements during isochronal annealing in predicting values for carrier removal rates. In addition, the trapping rates shown in Table I indicate that the $\mathrm{H} 5$ defect, when present at sufficlently high concentration, can be more effective as a hole trap than either $\mathrm{H} 3$ or $\mathrm{H} 4$. In the present case, the low post irradiation concentration of H5 tends to reduce its effectiveness as a recombination or trapping center. However, it ig found that the post irradiation concentration of this defect is observed to increase with increasing dopant concentration while the concentration of the remaining defects decreases. In fact, at a base dopant concentration of $10^{17} \mathrm{~cm}^{-3}$, the concentration of $\mathrm{HS}$ exceeds that of $\mathrm{H4}$ (5). Hence, at and above this concentration H5 could be more effective than either $\mathrm{H} 3$ or $\mathrm{H} 4$ in affecting the performance of InP solar cells after 1 MeV electron irradiation.

\section{Injection Anoaling}

It is known that considerable annealing of radiation induced degradation can be achieved by minority carrier injection, at room temperature, into p-type InP (2). In fact, some cell recovery has been observed when the cell was illuminated during irradiation. Hence, one would expect annealing in space, due to minority carrier injection, to be a major factor in alleviating the effects of radiation induced degradation. To determine the extent of this effect, one needs to perform simultaneous annealing while irradiating the cells at the low radiation fluxes encountered in space. A terrestrial experiment, duplicating the low fluxes observed in space, is impractical because of the extremely long times involved. Instead, we use a kinetic argument to estimate the effects of oimultaneous irradiation and annealing in space.

Following Heinbockel et al, the production rate of the jth defect is given by (6)

$d N j / d t=f j \sigma_{d} N_{a}(d \phi / d t)-W j N j$

where $\sigma_{f}$ is the cross section for atomic displacement, $N_{a}$ is the concentration of atoms, d $\phi / d t$ is the radiation flux, wj is the probability per unit time for annealing of the $j t h$ defect and fj is the fractional concentration of defect $\mathrm{Nj}$. At equllibrium dNj/dt is zero. Hence from equation 3 ,

$N j=\sigma_{d} N_{a} \phi_{e j}$

with $\phi_{e j}=f j(d \phi / d t) / W j$

Qej is defined as the effective fluence for production of the jth defect. In general, the effective fluence is the radiation fluence which would produce the equillibrium defect concentration in the absence of 
annealing $(6)$. In the present case we concern ourbelves with the post irradiation defect and preirradation carrier concentrations typical of those in the tables. In that case, 14 is considered to be the dominant defect in reducing cell output (1). Hence, evaluation of the effective fluence for H4 should result in an estimate of cell degradation in a specific orbit. In the present case, we evaluate an effective fluence for a satellite in geostationary orbit.

To evaluate $W j$ we use the relation obtained for injection annealing of $\mathrm{H} 4$ (2),

$W_{\text {inj }}=19.35 \mathrm{~J} \exp -\left(E_{A} / k T\right)$

where $J$ is the cell current density in $\mathrm{A} / \mathrm{cm} 2, \mathrm{E}_{\mathrm{A}}=0.133 \mathrm{eV}$ is the activation energy for injection annealing (2). The temperature $T=333 \mathrm{~K}$ is chosen as characteristic of arrays in Geo. Using these values with $\mathrm{J}=3 \times 10^{-2} \mathrm{~A} / \mathrm{cm}^{2}$ it ig found that $W_{\text {inj }}=5.64 \times 10^{-3} \mathrm{sec}^{-1}$. It is noted that we consider only injection annealing in the present case. This is justified by noting that, at this temperature, $W_{j n j}>W_{\text {th }}$ where the latter is the probability per unit time for thermal annealing (7).

The greatest uncertainty lies in obtaining values for the flux. This is estimated from a compilation of radiation measurements in space where integral electron fluxes in Geo are listed over the energy range from 0.04 to $7 \mathrm{MeV}$ (8). An upper limit to the flux is obtained by using the "worst case" integral fluence $\left(4.64 \times 10^{7} \mathrm{~cm}^{-2}\right.$ Bec-1) for electron energies greater than $0.04 \mathrm{MeV}(8)$. Hence, using $f=0.7$, we obtain $\phi_{\mathrm{f}}=5.8 \times 10^{9} \mathrm{~cm}^{-2}$ as the upper limit for the effective fluence due to electron irradiations in geostationary orbit. At this fluence, no cell degradation is expected (1). However one needs to be cautious in interpreting this result. Although steady state (or ambient) electron irradiations dominate over the ambient proton irradiations in Geo, the intermittent proton irradiations assoclated with solar flares are significant components of the space radiation environment (8). Although statistical models can be used to obtain rough estimates of the effects of solar flares, insufficient DLTS data exiets to enable inclusion of the effects of solar flares on the effective fluence. However, the present results are significant in the sense that electron irradiations predominate over protons in the ambient environment of this particular orbit.

\section{Conclusion}

Due to the controversy associated with identifying th.e atomic constitution of the defects observed by DLTS $(5,9)$ we have avolded designation of submicroocopic structures with the presently observed defects. However, it has been shown that hole trapping and carrier removal can be related to the behavior of apecifically labelled defects. Defect behavior has also been used to estimate the performance of Inp solar cells under simultaneous injection annealing and electron irradiation in geosynchronous orbit.

\section{References}

1. I. Weinberg, Solar Cella 31, p. 331 (1991).

2. M. Yamaguchi, K. Ando, A. Yamamoto and C. Uemura, J. Appl. Phys. 58, p. 568 (1985).

3. P.J. Drevinsky, C.E. Caefer and C.J. Keavney, Proceedings 3rd Int'l. Conf. on InP and Related Materiala, p. 56 (1991).

4. I. Heinberg, H.B. Curtig, C.R. Swartz, D.J. Brinker, P.P. Jenkins and $M$. Faur, Proceedings 22nd IEEE Photovoltaic Spec. Conf. 1991, to be Published.

5. M. Yamaguchi and K. Ando, J. Appl. Phys. 60, p. 935 (1986).

6. J.H. Heinbockel, E.J. Conway and G.A. Walker, Proceedings 14th Photovoltalc Spec. Conf., P. 1085 (1980).

7. M. Yamaguchl and $R$. Ando, J. Appl. Phya. 63, p. 5555 (1988).

B. E.G. Stassinopoulis and J.P. Raymond, Proceedings of the IEEE 76 , p. 1423 (1988).

9. A. sibile, $J$. suskl and $M$. Gilleron, J. Appl. Phys, 60, p. 595 1986. 
Table I: Introduction and Trapping Rates Used in Calculating $R_{c}$

\begin{tabular}{|c|ccc|ccc|c|}
\hline$c_{\text {Hole conc. }}$ & \multicolumn{2}{|c|}{ Introduction Rates } & Trapping Rates & P(Res)/ $\phi$ \\
\hline $\mathrm{cm}^{-3}$ & $\mathrm{I}_{3}$ & $\begin{array}{c}\mathrm{cm}^{-1} \\
\mathrm{I}_{4}\end{array}$ & $\mathrm{I}_{5}$ & $\mathrm{~T}_{3}$ & $\mathrm{~T}_{4}$ & $\mathrm{~T}_{5}$ & $\mathrm{~cm}^{-1}$ \\
\hline $\mathrm{a}_{2} .55 \times 10^{16}$ & 0.88 & 1.7 & 0.01 & 0.63 & 0.62 & 3.1 & 1.1 \\
\hline $\mathrm{b}_{4.1} \times 10^{16}$ & 0.82 & 1.2 & 0.04 & 0.63 & 0.62 & 3.1 & 1.1 \\
\hline
\end{tabular}

a From Fig. $1 ;{ }^{b}$ Intro. Rates from Ref. $3 ;^{c}$ Error $= \pm 5 \%$

Table II: Calculated and Measured Carrier Removal Rates

\begin{tabular}{|c|c|c|}
\hline$c_{\text {Hole Concentrations }}$ & \multicolumn{2}{|c|}{ Carrier Removal Rates } \\
\hline $\mathrm{cm}^{-3}$ & & $\mathrm{~cm}^{-1}$ \\
\hline & a Calculated & b Measured \\
\hline $2.4 \times 10^{16}$ & 2.7 & 2.8 \\
\hline $3.9 \times 10^{16}$ & 2.5 & 2.4 \\
\hline
\end{tabular}

a From Table $I ;{ }^{b}$ Independently Meas. (Ref. 4); ${ }^{c}$ Error $= \pm 58$

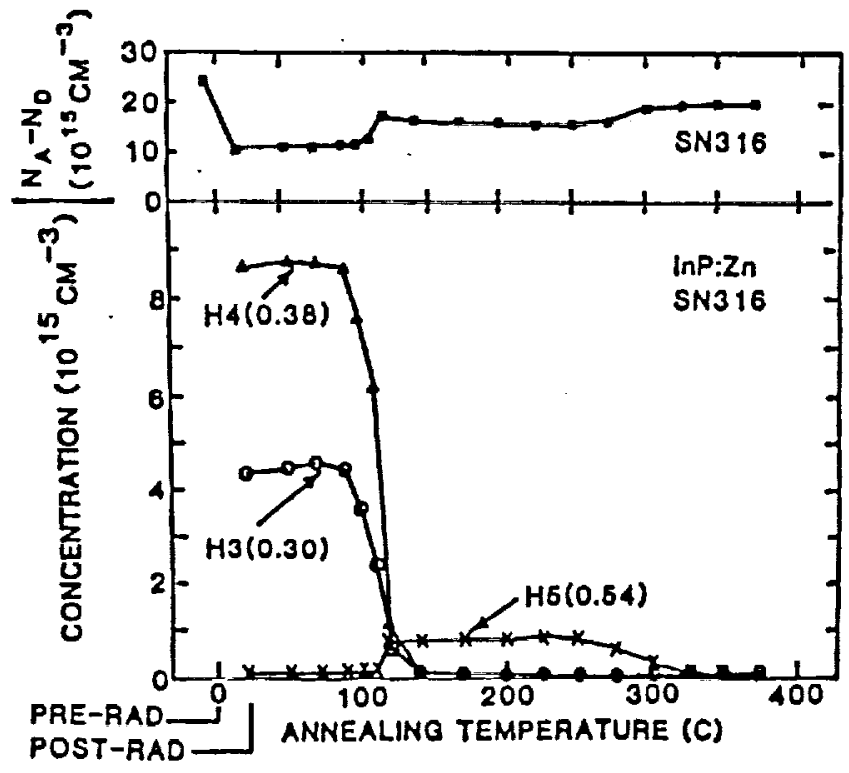

Figure 1. Isochronal Anneal After $1 \mathrm{MeV}$ Electron Irradiation $\left(\phi=5 \times 1015 / \mathrm{cm}^{2}\right)$ 


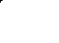

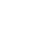


Public reporting burden for this collection of information is estimated to average 1 hour per response, including the time for reviewing instructions, searching existing data sources, gathering and maintaining the data needed, and completing and reviewing the collection of information. Send comments regarding this burden estimate or any ather aspect of this Davis Highway, Sute 1204, Arlington, VA 22202-4302, and to the Office of Management and Budget, Paperwork Reduction Project (0704-0188), Washington, DC 20503.

\begin{tabular}{|l|c|c|}
\hline 1. AGENCY USE ONLY (Leave blank) & $\begin{array}{c}\text { 2. REPORT DATE } \\
1992\end{array}$ & $\begin{array}{r}\text { 3. REPORT TYPE AND DATES COVERED } \\
\text { Technical Memorandum }\end{array}$
\end{tabular}

\section{TITLE AND SUBTITLE}

Defect Behavior, Carrier Removal and Predicted In-Space Injection

Annealing of InP Solar Cells

\section{FUNDING NUMBERS}

WU-506-41-11

\section{AUTHOR(S)}

I. Weinberg, C.K. Swartz, and P.J. Drevinsky

7. PERFORMING ORGANIZATION NAME(S) AND ADDRESS(ES)

National Aeronautics and Space Administration

Lewis Research Center

Cleveland, Ohio 44135-3191
8. PERFORMING ORGANIZATION REPORT NUMBER

E-6963

9. SPONSORING/MONITORING AGENCY NAMES(S) AND ADDRESS(ES)

10. SPONSORING/MONITORING AGENCY REPORT NUMBER

National Aeronautics and Space Administration

Washington, D.C. 20546-0001

NASA TM-105624

11. SUPPLEMENTARY NOTES

Prepared for the Fourth International Conference on Indium Phosphide and Related Materials cosponsored by IEEE and LEOS, Newport, Rhode Island, April 20-24, 1992. I. Weinberg and C.K. Swartz, NASA Lewis Research Center; P.J. Drevinsky, Phillips Laboratory, Bedford, Massachusetts 01731. Responsible person, I. Weinberg, (216) 433-2229.

12a. DISTRIBUTION/AVAILABILITY STATEMENT

Unclassified - Unlimited

Subject Category 33

13. ABSTRACT (Maximum 200 words)

Defect behavior, observed by DLTS, is used to predict carrier removal and the effects of simultancous electron irradiation and injection annealing of the performance of InP solar cells. For carrier removal, the number of holes trapped per defect is obtained from measurements of both carrier concentrations and defect concentrations during an isochronal anneal. In addition, from kinetic considerations, the behavior of the dominant defect during injection annealing is used to estimate the degradation expected from exposure to the ambient electron environment in geostationary orbit.

\begin{tabular}{|l|l|}
\hline 14. SUBJECT TERMS \\
Solar cells; Indium phosphide; Carrier removal; Injection \\
\hline $\begin{array}{l}\text { 17. SECURITY CLASSIFICATION } \\
\text { OF REPORT } \\
\text { Unclassificd }\end{array}$ & $\begin{array}{l}\text { 18. SECURITY CLASSIFICATION } \\
\text { OF THIS PAGE } \\
\text { Unclassified }\end{array}$
\end{tabular}

NSN 7540-01-280-5500 12b. DISTRIBUTION CODE 